\title{
Women's Birth Experience and Neonatal Outcomes, Study Design and Methodology with Baseline Characteristics. A Hospital-Based Maternal Follow- up Study
}

\section{Maleda Tefera ( $\square$ maledaifa.21@gmail.com )}

Haramaya University College of Health Sciences: Haramaya University College of Health and Medical Sciences

\section{Nega Assefa}

Haramaya University College of Health Sciences: Haramaya University College of Health and Medical Sciences

\section{Kedir Teji Roba}

Haramaya University College of Health Sciences: Haramaya University College of Health and Medical

Sciences

\section{Letta Gedefa}

Haramaya University College of Health Sciences: Haramaya University College of Health and Medical Sciences

\section{Study protocol}

Keywords: Mode of delivery, delivery experience, adverse birth outcomes.

Posted Date: May 7th, 2021

DOI: https://doi.org/10.21203/rs.3.rs-409199/v1

License: (c) (i) This work is licensed under a Creative Commons Attribution 4.0 International License. Read Full License 


\section{Abstract}

Background: Giving birth is a joyful, unique event and a highly individual experience in a woman's life. Childbirth experience has a significant role in developing self-confidence and positive feelings for the newborn. This experience is affected by many factors, including the mode of delivery. This paper tries to depict the experience of labor, delivery, and neonatal outcomes observed during the implementation of labor and delivery outcome study at selected hospitals in Eastern Ethiopia hospitals.

Method: A hospital-based follow-up study was implemented in Hiwot Fana and Jegula Hospital in Harar, Bisidimo hospital in Eastern Hararghe, Oromia, and Dil-Chora Hospital in Dire Dawa from June 2020 to October 2020. A total of 2246 women with labor experience visited the hospitals were followed from delivery until discharge to document their experience and neonates' outcomes. Data were collected through a face-to-face interview using a structured pre-tested questionnaire. A Phenomenological approach qualitative study design will also be employed from April to May 2021. The women who give birth to normal single-term newborns through vaginal or a cesarean section will be included in the study. Women with stillbirth twin, preterm and congenital malformation, serous ill neonates, and who admitted to for more than one week will be excluded because those women will be extreme or deviant cases. Indepth interviews coupled with tape recording and note-taking will be to collect the data. A semi-structured interview guide will consider four domains of the Roy adaptation theory: an open-ended question (physiological, self-concept, role and function, and interdependence). Translated files will be transferred to open code software in a plain text format. Coding and categorization will be done on a system to generate a synthesized theme.

\section{Discussion}

The study will provide a comprehensive evaluation of the birth experience and its neonatal outcome in Eastern Ethiopia. Understanding women's birth experience and neonatal outcome based on birth can help health professionals look inside themselves. It will form the foundation and development of a new guideline to improve maternity care.

\section{Plain English Summary}

A positive birth experience is a feeling of freedom, influential and respect. This experience can be affected by health professional support, emotional and psychological readiness, and delivery mode. Unnecessary cesarean section is associated with unwanted neonatal outcomes, which leads to a negative birth experience. This cesarean delivery can be control by vaginal birth after cesarean section for those who had one cesarean section delivery. No, much is known about women's birth experience, the neonatal outcome with the mode of delivery, and predictors of vaginal birth after cesarean section in the country.

Two thousand two hundred forty-six pregnant women who came to selected hospitals to give birth were included. The participants were asked about their past pregnancy history, current pregnancy history, and labor and delivery information. Directly after delivery, the condition of newborns was observed. Two 
hundred twenty women previous cesarean section delivery and tried vaginal birth were selected to identify the prognosticators of vaginal birth after cesarean section. From 2246 women, 1525 gave birth by vaginal delivery, and the rest were delivered by cesarean section.

\section{Introduction}

Globally near to three hundred eighty-six thousand women pass through the birth process every day (1), and women experience motherhood with feelings of happiness and challenges. Women's birth experience is influenced by perception or expectation during pregnancy, health service delivery system, support system, and delivery mode (2-5).

Maternity healthcare's primary purpose is to save women and their babies lives, to achieve this hospital system work hand in hand to ensure patient's safety and health condition (6). Besides delivering clinical care specific to labor and childbirth, it also means making sure that women are treated with respect and support. Continuity of care, regular monitoring and documentation of events, and clear communication between medical practitioners and clients are essential, ensuring that a referral plan is in place should more advanced medical care become necessary. These are all crucial elements that provide a positive birth experience (7). An effective referral system is an essential element of the health system to improve mothers and newborn outcomes(8). However, in developing countries, the referral system is not based on professional assessment; instead, it depends on women's preferences, and more than half of referrals are self-referral in the nations (9).

Labor can be a frightening experience for women; a safe hospital environment and continuous support would help the women relax and develop a positive experience $(10,11)$, also; it reduces the need for medical intervention and improves maternal and neonatal outcomes(12, 13). In most instances, women who delivered at health institutions safer from lack of respectful care, privacy, especially during pelvic examination and delivery, institutional regulation of not having a birth companion, and lack of emotional and physical support(14). Studies indicate that the mode of birth is also associated with a birth experience $(15,16)$.

The natural delivery mode is considered the safest for neonates. However, if this method is not achieved, operative vaginal or cesarean section (CS) is needed. (17). In most instances, operative vaginal or CS modes of delivery are associated with adverse maternal and neonatal outcomes. The common adverse neonatal outcomes related to operative vaginal or cesarean deliveries are Respiratory Distress Syndrome, Cephalohematoma, Shoulder Dystocia, feeding difficulties, Retinal hemorrhage, low Apgar score, Neonatal Intensive Care Unit (NICU) admission, mechanical ventilation, and neonatal deaths (17-20)

The best mode of delivery to improve maternal and neonatal outcomes remains the dilemma for obstetricians. However, the global adequate CS rate and the increasing number of CS deliveries have been debated among health care providers because most deliveries occur in Sub-Saharan Africa $(21,22)$. In Ethiopia, the CS rate has also been increased dramatically from $0.7 \%$ in 2000 to $1.9 \%$ in 2016 (23). 
Little is known about women's birth experience and its neonatal outcome. We are undertaking this maternal surveillance study to address this gap, focusing on admission, delivery through postpartum, and discharge. The study will investigate women's birth experience, neonatal outcome, and trial of labor outcomes. This paper tries to depict the population and flow of study. This analysis will give a baseline on the status of obstetrics care and supports developing new guidelines and strategies to improve maternal and newborn care.

\section{Methods And Materials}

\section{A study Area}

This maternal surveillance study is a hospital-based prospective follow-up study of women's birth experience and its outcomes carried out in two rounds. The first participants were enrolled in the study from June 1, 2020, to October 30, 2020. The second round will commence from April 1, 2020, and the qualitative data collection is expected to end on May 30,2021. The hospitals included in the study were from Eastern Hararghe (Oromia region), Harari region, and Dire Dawa administration. There are nine government hospitals in the study area altogether, one specialized hospital (Hiwot Fana Hospital), one referral hospital (Dil-Chora hospital), five generals/secondary hospitals, and two primary hospitals. In this study, Hiwot Fana and Jegula Hospital from Harar, Dil-Chora Hospital from Dire Dawa, and Bisidimo Hospital from Eastern Hararghe were included (Figure_1).

\section{Hiwot Fana Specialized Hospital (HFSH)}

HFSUH is one of the oldest hospitals in Harar, established during the Italian occupation (1928-1933). In the recent two-three decades, the hospital becomes a teaching facility for health sciences students for Haramaya University. It has a total of 233 beds for admission. The annual number of patients visiting the hospital reached 114,650, with an average of 11,957 admissions per year. (24). The maternity unit offers service for about 5808 deliveries annually and provides 830 caesarian deliveries annually (25). Babies born with adverse outcomes are transferred to a 15 beds neonatal intensive care unit (NICU). It admits 124 neonates per month on average.

\section{Jugal Hospital}

Jugal hospital is also the oldest hospital in Ethiopia. It was built in 1957 EC by King Haile Selase in memory of his father, Ras Mekonen. The maternity unit has six prenatal beds, two delivery couches, one newborn resuscitation bed, and eight postnatal beds. In this unit, on average, 3000 deliveries are conducted annually. Neonates with health problems are admitted to the NICU. It has six beds, three incubators, three radiant warmer, and one oxygen tanker. On average, 30 neonates are admitted per month, and severe cases are referred to Hiwot Fana (26).

\section{Dil-Chora Hospital}


Dil-Chora hospital is the largest and referral facility in Dire Dawa. The hospital has six wards and an ICU with a total of 353 beds. Around 193485 patients visit the hospital annually, nearly 17,512 patients visit the hospital for inpatient service per year. The maternity ward gives service for laboring women and their babies. In this ward, there are three departments (delivery, maternal, and child health (MCH) and NICU) (27).

\section{Bisidemo Hospital}

Bisidimo Hospital is in eastern Hararghe, Babile district, $20 \mathrm{~km}$ away from Harar eastwards. It was established in 1958 by Deutsches Aussãtzigen Hilfswerk (DAHW) (German Leprosy Relief Organization). Bisidimo hospital is the center of leprosy in the East Hararghe zone of the Oromia region. The hospital provides service for 1700 laboring women annually and has one emergency surgeon(28).

\section{Study design for Quantitative Studies}

This is a follow-up study capturing pregnant women on arrival to the labor ward to follow through delivery, postpartum, and discharge. A total of 2246 pregnant women who visited the selected hospital for labor were included to document their labor, delivery, discharge experiences, and outcomes. The follow-up started on admission. At the entrance, past and current maternal history were taken from the women. The women were followed through observation during labor/delivery. The maternal chart was also reviewed to get information to meet the required information for analysis; after delivery, neonatal outcomes were assessed and followed until discharged from the hospital. The women who had previous CS and tried vaginal delivery were included in the study. (Figure 2)

\section{Study Population and sampling}

This study's source populations were all women who attended the hospitals for labor and delivery during the study period. Among these, women who delivered a live baby and volunteer to participate in the study were included. Based on the hospitals' information available, approximately 7,000-8000 women gave birth in the previous six-month period. More than $50 \%$ of these were from rural areas, and of these, $25 \%$ were from Haramaya, Aweday, Fedis, Konbolicha, and Jarso. (Figure 2).

A total of 2246 women were recruited at admission. Systematic random sampling was used to select the participants; $\mathrm{N} / \mathrm{n}==7,536 / 2246=3.35$. (Figure3)

\section{Sample size determination.}

The sample size for each objective was determined using online Epi-Open software (Table 1)

\section{Inclusion and Exclusion Criteria}

Women who have visited the hospitals for delivery with their babies were included. Women who were given birth at home or other facilities and visited the hospitals for the management of complications were 
excluded. Women with critical medical conditions and women with known intrauterine fetal death were excluded from the study.

\section{Enrollment and Follow-up}

Recruitment of study participants took place at the delivery ward of selected hospitals. Women who fulfill the inclusion criteria were explained and invited by the trained research assistants to participate in the study. Once the women accepted the invitation, they were asked for consent. The data collectors gather baseline information on sociodemographic characteristics and maternal information from health professional/medical records. A maternal chart review was also done to get information about labor and the outcomes.

The cohort identification number was filled for enrolled participants and informed them to keep this sheet after delivery. The cohort number was also written on the maternal chart to trace back those who missed the sheet. All women delivered vaginally (spontaneous and operative vaginal delivery) and cesarean section (emergency and Elective CS) were included in the study. The newborns were followed from the time of delivery to discharge from the hospital.

\section{Data Collection and instrument}

Four female midwives and two neonatal nurses from respective hospitals were selected and trained to collect the data. The research team supervises data collection. A structured questionnaire translated into local languages (Amharic Afan-Oromo and Somali) was used for data collection.

Socio-demography, economic condition, past-current obstetric history, and labor-delivery information including party, gravid, current and previous obstetric history, antenatal care(ANC), history of previous CS, history of successful Vaginal birth after CS(VBAC), history stillbirth, birth interval, delay the second stage of labor Premature Rupture of Membrane(PROM), cephalo-pelvic disproportion (CPD), induced labor, and gestational age and mode of delivery were collected using several forms. Fetal and neonatal information includes mal-presentation, position, sex, and weight. The baby's outcomes include trauma, hypothermia, MAS, and breastfeeding difficulty, were assessed using a physical examination checklist (Table 2).

\section{Quality Control}

The questionnaire was pre-tested for consistency and validity in one of the nearby hospitals, Haramaya hospital, which is not part of the study. For wealth index and major neonatal outcome, validated tools were used. Adequate training was given for data collectors and supervisors. The focal persons and principal investigators closely followed the data collection process and ensured complete data consistency. Any error, ambiguity, incompleteness, or any other problems were addressed the following day. Data were double entered into Epi Data software to check for the agreement of data.

\section{Data Management}


Data were entered using the EpiData and exported to STATA Statistical for analysis, and it was cleaned, edited, and recorded before analysis. Cleaning was done through visual inspection, running frequencies, and cross-tabulation. The error was corrected by checking the questioner's hard copy, and for some ambiguous answers, the data collectors were asked to get clarity. Besides, the maternal chart and registrations were checked.

Missing data were handled using complete case analysis, missing coding values as separate categories, imputation methods, and/or sensitivity analyses. Some variables were recorded to make a clear interpretation, and the new variables were generated from the existing one. Then descriptive statistics was using numbers, percentages, mean, and standard deviation were done. This study's outcomes are categorical, and the appropriate statistical test is the chi-square test or Fisher's exact test to analyze the relationship between the variables with $p<0.05$.

\section{Study design for Qualitative Studies}

Phenomenological (cf Husserl, Heidegger) approach qualitative study design will be employed Aprile to May 2021. The phenomenological approach aims to develop a complete, accurate, clear, and articulate description and understanding of a particular human experience or experiential moment(32).

\section{Study population}

The study participants will be all women who give birth at selected hospitals. The women who give birth to normal single-term newborns through vaginal or a cesarean section will be included in the study.

\section{Inclusion criteria and Exclusion criteria}

All women with a singleton term, without pregnancy-related complication, like mothers with APH, Preeclampsia, eclampsia, and diabetics melts, and who can talk to the local language, will be included in the study. On the other hand, women with stillbirth twin, preterm and congenital malformation, serous ill neonates, and who admitted to for more than one week will be excluded because those women will be extreme or deviant cases.

\section{Sampling technique}

Women visiting the two hospitals for labor and delivery one to two weeks before the interview will be interviewed. This framework allows us to get fresh memory of women's birth experiences. To get in-depth information and to indicate different backgrounds, women will be categorized into two groups based on the mode of delivery and the number of delivery exposure. The women will be categorized into two groups. The women give birth by vaginal delivery and cesarean section; then these will be further divided into sub-groups. The first subgroup will be primiparous women, the women who have no previous exposure for delivery. 
These women will have a different experience because their perception about childbirth, emotional readiness, and delivery room environment might affect their experience. Still, those women who have previous delivery exposure would not be affected by such factors. Women who had previous CS scare and delivered by vaginal delivery will be the second sub-group.

To illustrate these particular subgroups of interest and facilitate comparisons, stratified purposeful sampling will be employed. Stratified purposeful samples are samples within samples where each stratum is fairly homogenous. The purpose of stratified purposeful sampling is to capture major variations even though a common core may also emerge in the analysis ((33). It is also helpful for examining the variations in the manifestation of a phenomenon as any key factor associated with the phenomenon is varied. (34).

\section{Sample size}

The sample size is determined based on the level of information saturation and the variety of ideas among the sub-groups. Data saturation involves sampling until no new information is obtained and redundancy is achieved. A minimum of 3 women from each group will be interviewed.

\section{Participants' recruitment}

Before the preliminary recruitment visit is conducted in the health institutions to discuss with the women, during this visit, information will be provided on volunteer participation, the study's aim, method, and to get verbal consent for the prospective home visit re-visit in the hospital. The full address of volunteers will be taken during this period, and the convenient place and time of the interview will be arranged within the first two weeks of delivery.

\section{Data collection procedure}

The trained facilitator will conduct in-depth interviews coupled with tape recording and note-taking in the natural setting. A semi-structured interview guide will be used for a dynamic operation between the researcher and the study participants. The guide will include four domains of the Roy adaptation theory: an open-ended question (physiological, self-concept, role and function, and interdependence) and some additional questions. Before the interview, written informed consent will be secured from the participant. Detailed information will be given to the women about its benefit, risks, and potential termination if they do not like to continue with the discussion. The interviewer will inform about ensuring confidentiality and the use of data.

The in-depth interviews will be conducted by two data collectors and one facilitator who can fluently speak Amharic and Afan Oromo. When one data collector is the interviewer, the second will be the notetaker, and the lead researcher facilitates the interview. English version interview guide will be translated into Amharic and Afan Oromo language. All interviews will be audio-recorded. The women will be interviewed in a separate room. 
After the opening question, to encourage the participant to describe their experience probing words will be used. This includes "Tell me more," "what will next," and"please elaborate." finally, the opportunity will be provided for the participants for further discussion. Notes will be taken parallel to the interview. The note taker will record the women's reactions such as laughter, crying, eye contact, facial expression, a sign of fear and discomfort. The facilitator will transcribe the data daily.

\section{Data processing and analysis}

The audiotape's records will be transcribed verbatim to Amharic and translated to English. The consistency of translation will be checked with the records and notes taken. Translated files will be transferred to open code software in a plain text format. Coding and categorization will be done on a system to generate a synthesized theme. Based on existing and emergent themes, ideas meanings will be generated. Themes identified from literature are: getting ready fear and anxiety from labor pain, lack of information and unfamiliarity with the process of labor and the delivery room, the need for support, the support of a midwife, husband, family, and friends, the role of the relationship with caregivers and the father during delivery, privacy, perceived control, emotion, satisfaction, first moments with the baby, imagining a second pregnancy.

The analysis will be done theme by theme to give meaning based on memos generated from each code and category. Data analysis will be done following each interview to learn, understand, and consolidate each theme and research group's information. Lastly, validation and finalization will be done, and the experiences of two groups of women will be narrated substantiated with quotations.

\section{Data quality}

The trustworthiness of data will be kept throughout the procedure, using five common methods. After finishing the interview, the interviewer summarized the participants' responses to increasing the data's credibility, who could approve the data's exactness. The finding will be checked by the researcher and senior researchers to address credibility using peer debriefing. During data collection, the interviewer used the same interview guide for each participant for probing data. A note will be taken for an unusual reaction of the participant to address dependability.

The researchers also checked the purposes, methods, and procedures to enhance the rigor of research findings. The complete transcription will be matched with the audio records to confirm the consistency of the result. Several methods will be used to achieve a high level of validity and quality in the data, which is the particular concern of qualitative study; emphasis will be given for confidentiality, to create comfort and comfortable environment for the participants to share more intimate details and to engage in more comprehensive descriptions of their experiences.

Besides, the pre-test will be done to validate the interview guide at Haramaya hospital, and correction will be taken accordingly to obtain a rich data set. Transferability will also be addressed using a purposive 
sampling method to get information-rich participants, and during the interview, the researcher tried to get in-depth information.

\section{Baseline characteristics of participants}

A total of 2246 eligible pregnant women were included in the surveillance; of these, $1525(67.9 \%)$ had a vaginal delivery and $721(32 \%)$ cesarean section. The proportion of cesarean section delivery was $32 \%$ $(95 \% \mathrm{Cl} 0.30,0.34)$. The majority of the women were in the age group of $25-34(50.45 \%)$, married $(98.5 \%)$, Muslim by religion (75.3\%), of Oromo ethnic group (73.2\%), had a minimum of primary education (69\%) and housewife (71.6\%) (Table 3).

\section{Discussion}

The prospective follow-up study was set to explore women's birth experience and investigate neonatal outcomes. This paper tried to describe maternal and baby recruitment flow to the survey and characterize the study population as a background for other analysis as a baseline.

The total number of women included in the study was 2246 , and 2117 singleton babies were included. The magnitude of cesarean section delivery was $32 \%$, almost similar to studies conducted in other Ethiopian parts (35-38).

Despite increased CS rates, neonatal outcomes have not improved $(39,40)$. Women's birth experience also varies due to this change in the mode of delivery(41). The follow-up study using quantitative and qualitative methods helps to have a better understanding of the subject under discussion; both the health professional and the participant benefited from this type of study. The health profession recognized the benefits and risks of cesarean section and women's feelings about the service they offer, which may provide an essential clue to develop new strategies to increase the quality.

This study tried to include clients at the first level and referral hospital, which provides a good mix of the client's character. It has also followed a large number of pregnant women through the labor and delivery process using a combination of methods, including interview, observation, and chart review. It has also tried to show the gap of service given at the hospitals using a qualitative investigation. Authors would like to alert readers that the follow-up was started at the time of labor; this might lead to missed some critical variable, such as the pattern of weight gain, BMI, preference of mode delivery at the first, second, and third trimester, and the neonates were followed only until the discharge from the hospital, which might not give a complete picture of the neonatal period.

\section{Abbreviations}

ANC: Antenatal Care

CS: Cesarean Section 
CPD: Cephlo Pelvic Disproportion

ECS: Elective CS.

EC: Ethiopian Calendar

HFSH: Hiwot Fana Specialized Hospital

MAS: Meconium Aspiration Syndrome

MCH: Maternal and Child Health

NICU: Neonatal Intensive Care Unit

PROM: Premature Rupture of Membrane

RDS: Respiratory Distress Syndrome

SD: Standard Division

VBAC: vaginal birth after CS.

\section{Declarations}

\section{Ethical Declaration}

Ethical clearance was obtained from the College of Health and Medical Sciences Institution Health Research Ethical Review Committee (Ref.no. IHRERC/107/2020), Haramaya University. The purpose, procedure and duration, possible risks, and benefits of the study explain using the local language. Then individual informed, voluntary, written, and signed consent was taken.

\section{Consent for publication}

Not applicable

\section{Availability of data and materials}

All the data of this study are available from the corresponding author upon request

\section{Competing interests}

The authors declared that they have no competing interests

\section{Funding}

The study is Ph.D. work, and the author(s) disclosed receipt financial support for data collection from Haramaya University as part of higher education research sponsorship. 


\section{Authors' contributions}

MT designed the study, participated in data collection, and analyzed and interpreted the results under the supervisor of NA. KT and LG. NA reviewed the draft result and approved the result. All authors read and approved the final manuscript.

\section{Affiliations}

School of Nursing and Midwifery, College of Health and Medical Sciences, Haramaya University, Harar, Ethiopia.

Maleda Tefera, Nega Assefa and Kedir Teji

School of Medicine, College of Health and Medical Sciences, Haramaya University, Harar, Ethiopia Letta Gedefa

\section{Corresponding author}

Correspondence to Maleda Tefera.

\section{Acknowledgments}

We acknowledge Haramaya University, college of health and medical sciences, for funding. Our special gratitude goes to data collectors and health professionals who work at the obstetric ward and NICU for their unreserved commitment and support.

\section{Authors' information}

MT is a Ph.D. student at Haramaya University, has a Master in pediatric and child health nursing, and is currently working at the College of Health and Medical Science, School of nursing and midwifery, Haramaya University Harar, Ethiopia. NA and KT (Ph.D. Associate professors) are researchers and currently working at the College of Health and Medical Sciences, Haramaya University. L.D. is (Gynecologist, assistant professor) working at the College of Health and Medical Sciences and HFSH.

\section{References}

1. UNICEF. Nearly 386,000 children will be born worldwide on New Year's Day, says UNICEF New York: 2018 2018. Report No.

2. Downe S, Finlayson K, Oladapo O, Bonet M, Gülmezoglu AM. What matters to women during childbirth: a systematic qualitative review. PloS one. 2018;13(4):e0194906.

3. Cook K, Loomis C. The Impact of Choice and Control on Women's Childbirth Experiences. The Journal of perinatal education. 2012;21(3):158-68. 
4. Guittier M-J, Cedraschi C, Jamei N, Boulvain M, Guillemin F. Impact of mode of delivery on the birth experience in first-time mothers: a qualitative study. BMC pregnancy and childbirth. 2014;14(1):254.

5. Oweis A, Abushaikha L. Jordanian pregnant women's expectations of their first childbirth experience. International Journal of Nursing Practice. 2004;10(6):264-71.

6. Danlami YM, Almu A, Mairoh H, Hamza MK. Integrating Antenatal and Postnatal Pregnancy Services to Hospital Management System. Traektoriâ Nauki= Path of Science. 2018;4(10).

7. WHO. WHO recommendations:: intrapartum care for a positive childbirth experience. Sexual and reproductive health. 2018.

8. Organization WH. Standards for improving quality of maternal and newborn care in health facilities. 2016.

9. Jahn A, Debrouwere V. Referral in Pregnancy and Childbirth: Concepts and Strategies. Safe Motherhood Strategies: A Review of the Evidence. 2000;17.

10. Hodnett ED. Pain and women's satisfaction with the experience of childbirth: a systematic review. American journal of obstetrics and gynecology. 2002;186(5):S160-S72.

11. Organization. Counselling for maternal and newborn health care: a handbook for building skills. World Health Organization; 2010.

12. Campbell DA, Lake MF, Falk M, Backstrand JR. A randomized control trial of continuous support in labor by a lay doula. Journal of Obstetric, Gynecologic \& Neonatal Nursing. 2006;35(4):456-64.

13. Bohren MA, Hofmeyr GJ, Sakala C, Fukuzawa RK, Cuthbert A. Continuous support for women during childbirth. Cochrane Database of Systematic Reviews. 2017(7).

14. Gashaye KT, Tsegaye AT, Shiferaw G, Worku AG, Abebe SM. Client satisfaction with existing labor and delivery care and associated factors among mothers who gave birth in university of Gondar teaching hospital; Northwest Ethiopia: institution based cross-sectional study. PloS one. 2019;14(2):e0210693.

15. Velho MB, Atherino dos Santos EK, Brueggemann OM, Camargo BV. Experience with vaginal birth versus cesarean childbirth: integrative review of women's perceptions. TEXTO \& CONTEXTO ENFERMAGEM. 2012;21(2):458-66.

16. Husby AE, van Duinen AJ, Aune I. Caesarean birth experiences. A qualitative study from Sierra Leone. Sexual \& Reproductive Healthcare. 2019;21:87-94.

17. Demissie K, Rhoads GG, Smulian JC, Balasubramanian BA, Gandhi K, Joseph K, et al. Operative vaginal delivery and neonatal and infant adverse outcomes: population based retrospective analysis. Bmj. 2004;329(7456):24.

18. Wen SW, Liu S, Kramer MS, Marcoux S, Ohlsson A, Sauvé R, et al. Comparison of maternal and infant outcomes between vacuum extraction and forceps deliveries. American journal of epidemiology. 2001;153(2):103-7.

19. Towner D, Castro MA, Eby-Wilkens E, Gilbert WM. Effect of Mode of Delivery in Nulliparous Women on Neonatal Intracranial Injury. Obstetrical \& Gynecological Survey. 2000;55(5):276-7. 
20. Finn D, O'Neill SM, Collins A, Khashan AS, O'Donoghue K, Dempsey E. Neonatal outcomes following elective caesarean delivery at term: a hospital-based cohort study. The Journal of Maternal-Fetal \& Neonatal Medicine. 2016;29(6):904-10.

21. Patel RV, Gosalia EV, Deliwala KJ, Vasa PB, Pandya VM. Indications and trends of caesarean birth delivery in the current practice scenario. Int J Reprod Contracept Obstet Gynecol. 2014;3(3):575-80.

22. Shamsa A, Bai J, Raviraj P, Gyaneshwar R. Mode of delivery and its associated maternal and neonatal outcomes. Open Journal of Obstetrics and Gynecology. 2013;3(03):307.

23. Yisma E, Smithers LG, Lynch JW, Mol BW. Cesarean section in Ethiopia: prevalence and sociodemographic characteristics. The Journal of Maternal-Fetal \& Neonatal Medicine. 2019;32(7):1130-5.

24. HFUSH-HR. services delivered and human resource in HFUSH. 2019.

25. HFUSH-HMIS. patient flow of hiwot fana specialized university hospital. 2019.

26. JUGAL-HMIS. Patient flow of the Jugal hospital. 2019.

27. HMIS-DILCHORA. Hospital profile and human resorce 2020.

28. HMIS-BISIDIMO. Patient flow of Bisidimo hospital 2020.

29. Halil H, Abdo R, Hellil S, Kedir R. Predictors of Cesarean Section among Women Delivered at Durame General Hospital, Southern Ethiopia. J Women's Health Care. 2020;9(482):2167-0420.20.

30. Liston FA, Allen VM, O'Connell CM, Jangaard KA. Neonatal outcomes with caesarean delivery at term. Archives of Disease in Childhood-Fetal and Neonatal Edition. 2008;93(3):F176-F82.

31. Birara M, Gebrehiwot Y. Factors associated with success of vaginal birth after one caesarean section (VBAC) at three teaching hospitals in Addis Ababa, Ethiopia: a case control study. BMC Pregnancy Childbirth. 2013;13:31.

32. Schacht R. Husserlian and Heideggerian Phenomenology. Philosophical Studies: An International Journal for Philosophy in the Analytic Tradition. 1972;23(5):293-314.

33. Patton MQ. Qualitative interviewing. Qualitative research and evaluation methods. 2002;3(1):344-7.

34. Suri $\mathrm{H}$. Purposeful sampling in qualitative research synthesis. Qualitative research journal. 2011;11(2):63-75.

35. Gedefaw G, Demis A, Alemnew B, Wondmieneh A, Getie A, Waltengus F. Prevalence, indications, and outcomes of caesarean section deliveries in Ethiopia: a systematic review and meta-analysis. Patient Safety in Surgery. 2020;14(1):11.

36. Bago BJ. Prevalence and its associated factors among women undergone operative delivery at Hawassa University comprehensive specialized hospital, southern Ethiopia, 2017. Gynecol Obstet. 2018;8.

37. Tsega F, Mengistie B, Dessie Y, Mengesha M. Prevalence of cesarean section in urban health facilities and associated factors in eastern Ethiopia: hospital based cross sectional study. J Preg Child Health. $2015 ; 2$. 
38. Melese A. Magnitude of cesarean section delivery and its associated factors among mothers who gave birth at public hospitals in north wollo zone, northern Ethiopia. (Msc dissertation, Haramaya University)2019 2019//.

39. Ye J, Zhang J, Mikolajczyk R, Torloni MR, Gülmezoglu A, Betran A. Association between rates of caesarean section and maternal and neonatal mortality in the 21 st century: a worldwide populationbased ecological study with longitudinal data. BJOG: An International Journal of Obstetrics \& Gynaecology. 2016;123(5):745-53.

40. Gondwe T, Betha K, Kusneniwar GN, Bunker CH, Tang G, Simhan H, et al. Adverse infant outcomes associated with caesarean section delivery in India. International Health. 2019;12(5):411-6.

41. Aksoy M, Aksoy AN, Dostbil A, Celik MG, Ince I. The relationship between fear of childbirth and women's knowledge about painless childbirth. Obstet Gynecol Int. 2019;2014.

\section{Tables}

Table 1: population and sample size

\begin{tabular}{|c|c|c|}
\hline Objectives & Description & $\begin{array}{l}\text { Sample } \\
\text { size }\end{array}$ \\
\hline $\begin{array}{l}\text { Indications, } \\
\text { pattern, and } \\
\text { determinants of } \\
\text { cesarean delivery }\end{array}$ & $\begin{array}{l}\text { Taking maternal age as one of the key variables, the sample size } \\
\text { based on a study conducted in South Ethiopia }(29) \text { and } 95 \% \\
\text { confidence level, } 80 \% \text { power is the margin of error } d=5 \%(0.05)\end{array}$ & 1,135 \\
\hline $\begin{array}{l}\text { Neonatal } \\
\text { outcomes in } \\
\text { relation to mode } \\
\text { of delivery }\end{array}$ & $\begin{array}{l}\text { With the assumption of } 95 \% \mathrm{Cl} \text { with power } 80 \text {, Comparison of } \\
\text { operative vaginal delivery and spontaneous vaginal delivery with the } \\
\text { outcome of major trauma of the newborn } \mathrm{p} 1=1.4, \mathrm{p}=0.2(30) \text {, }\end{array}$ & 2246 \\
\hline $\begin{array}{l}\text { Predictors for the } \\
\text { success of trial } \\
\text { of labor after } \\
\text { previous CS } \\
\text { delivery }\end{array}$ & $\begin{array}{l}\text { Considering } 95 \% \text { confidence interval, power of } 80 \% \text {, presence of } \\
\text { amniotic fluid used as a predictor. Unexposed with outcome } 29 \% \text {, } \\
\text { exposed with outcome } 47 \% \text { and OR=2.20, } R=1: 1(31) \text {, the final } \\
\text { sample size is } 231 \text { with a } 5 \% \text { non-response rate. }\end{array}$ & $\begin{array}{l}116 \text { for } \\
\text { the case } \\
\text { and } 115 \\
\text { for } \\
\text { control }\end{array}$ \\
\hline
\end{tabular}

Table 2: Data Collection instruments

A-Socio-demographic characteristics of the women 


\begin{tabular}{|c|c|}
\hline Age in year & _year \\
\hline \multirow[t]{2}{*}{ Resident } & 1.Urban \\
\hline & 2.Rural \\
\hline \multirow[t]{4}{*}{ Address } & 1.Harari region \\
\hline & 2.Dire Dawa Administration \\
\hline & 3.East Hararghe \\
\hline & 4.Somali region \\
\hline \multirow[t]{4}{*}{ Religion } & 1.Muslim \\
\hline & 2.Orthodox \\
\hline & 3.Protestant \\
\hline & 4.Others specify --_- \\
\hline \multirow[t]{4}{*}{ Current marital status } & 1.Single \\
\hline & 2.Married \\
\hline & 3.Divorced \\
\hline & 4.Widowed \\
\hline \multirow[t]{5}{*}{ Ethnicity } & 1.Oromo \\
\hline & 2.Amhara \\
\hline & 3.Harari \\
\hline & 4.Gurage \\
\hline & 5.Others --- \\
\hline \multirow[t]{6}{*}{ Educational status } & 1.Unable to read \& write \\
\hline & 2.1-4 grade \\
\hline & 3.5-8grade \\
\hline & $4.9-12$ grade \\
\hline & 5.Diploma \\
\hline & 6.Degree and above \\
\hline \multirow[t]{3}{*}{ Occupation } & 1.Government employed \\
\hline & 2.Private employed \\
\hline & 3.NGO employed \\
\hline
\end{tabular}

Page 16/28 
4.Day laborer

5.Self-employed

6.House wife

7.0thers----

B-Past and current obstetric history of the women 


\begin{tabular}{|c|c|}
\hline Questions & Response \\
\hline Number of pregnant (gravidity) & - \\
\hline Number of birth (Parity) & \\
\hline \multirow[t]{2}{*}{ Did you Have CS scare } & 1.Yes \\
\hline & 2.No \\
\hline If Yes, how many & $\longrightarrow$ \\
\hline \multirow[t]{2}{*}{ Types CS } & 1.Emergency CS \\
\hline & 2.ECS \\
\hline Indication for CS & $\longrightarrow$ \\
\hline \multirow[t]{3}{*}{ The newborn outcome of previous CS } & 1.Alive \\
\hline & 2.Stillbirth \\
\hline & 3.Early neonatal death \\
\hline \multirow[t]{2}{*}{ History trial of labor after CS delivery } & 1.Yes \\
\hline & 2.No \\
\hline \multirow[t]{2}{*}{ If yes, how was the outcome } & 1.Success \\
\hline & 2.Failure \\
\hline \multirow[t]{2}{*}{ Presence of prior vaginal birth (before CS) } & 1.Yes \\
\hline & 2.No \\
\hline If, yes how many & $\longrightarrow$ \\
\hline \multirow[t]{2}{*}{ History of abortion } & 1.Yes \\
\hline & 2.No \\
\hline \multirow[t]{2}{*}{ History of preterm delivery } & 1.Yes \\
\hline & 2.No \\
\hline \multicolumn{2}{|l|}{ History of low birth weight } \\
\hline \multirow[t]{2}{*}{ History of stillbirth } & 1.Yes \\
\hline & 2.No \\
\hline \multirow[t]{2}{*}{ History of early neonatal death } & 1.Yes \\
\hline & 2.No \\
\hline Gestational age & week \\
\hline
\end{tabular}




\begin{tabular}{|ll|}
\hline Do you utilize ANC during your current pregnancy & 1.Yes \\
\hline If yes, when did you initiate & \\
\hline How many time you utilize ANC during your current pregnancy & \\
\hline Is there any complication of current pregnancy & 1.Yes \\
\hline If yes, what are the complications & 2.No \\
\hline Inter-delivery interval & \\
\hline Interval of birth from last previous CS & \\
\hline
\end{tabular}

C- Labor- Delivery and Newborns characteristics 
Questions

Do refer from $\mathrm{HC}$ or hospital

If yes, what is the reason

If yes, Travel time from Health center/Hospital to referral/general hospital(minutes)

Diagnosis at admission

Onset of labor

1.Spontaneous

If the onset of labor is induction, what is the reason

Augmentation of labor

1.Yes

2.No

Partograph follow up

1.Yes

2.No

If yes, is the partograph followed strictly

1.Yes

2.No

Status of amniotic fluid

1.Clear (C)

2.Meconium stained(M)

3.Bloodstained (B)

Presence of premature rupture of membrane (PROM)

1.Yes

2.No

If yes, the time of PROM

$1 .>12$ hours

2.

\section{$<12$ hours}

Cervical dilatation at admission in $\mathrm{cm}$ $\mathrm{cm}$

Cervical effacement $\%$

Station of presenting part at admission

Position of presenting part

Duration of labor after admission hrs.

Presentation of the fetus during delivery

Types of a mode of delivery

If operative vaginal deliver, what is the indication

If CS, what is the indication o

Time from admission to surgery decision (hours)

$\mathrm{hr}$.

The decision to incision interval (minutes) $\min$

CS is performed by

Qualification Health Provider who assist the delivery (SVD/OVD) 
Outcomes immediately after birth

New born charcterstics

Sex of newborn

Weight of the newborn

Height of the newborn

First min Apgar score

Five min Apgar score

Delay in initiating and maintaining respiration (depression at birth)

Birth asphyxia

If yes, its severity

Presence of MAS

If yes, what is its severity

Respiratory distress

If yes, what is its severity

Birth trauma

If yes, type birth trauma

Congenital malformation

If yes, type

Newborn outcome
1.Male 2. Female gm. $\mathrm{cm}$

$\begin{array}{ll}\text { 1.Yes } & \text { 2.No } \\ \text { 1.Yes } & \text { 2.No }\end{array}$

1.Yes

2.No

1.Yes

2.No

1.Yes

2.No

1.Minor trauma ${ }^{+}$

2.Major trauma ${ }^{++}$

1.Yes 2.No

2.No

1.Minor

2.Major

1.Alive

2.Death

\section{D-Neonatal outcomes checklist}


Questions

Assessment after one hour

Initiation of breastfeeding within $1 \mathrm{hr}$

Breastfeeding difficulty(rooting sucking reflex)

Moro reflex

Grasp reflex

Hypothermia $\mathrm{T}^{0}<36{ }^{0} \mathrm{C}$

Neonatal outcome

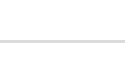

\section{If Early neonatal death, what is the reason}

Is the newborn admitted to NICU

If yes, Reason for NICU

Need respiratory support

If Yes, what type is it

\section{Response}

\section{Yes}

2.No

1.Yes

2.No

1.Yes

2.No

1.Yes

2.No

1.Yes

2.No

1.Alive

2.Early neonatal death

1.Yes

2.No

1.Yes

2.No

Mechanical ventilation

CPAP

Oxygen flow

Endo-tracheal tube

Others specify

\section{Assessment after 24 to discharge from the hospitals}

Is the neonate has health problem after delivery/admitted to NICU

1.Yes

2.No

If yes, what is the condition of the neonate

1.Improve

2.The same

3.Dead

If dead, what is the reason for death

What is the neonate who was normal after delivery (not admitted to NICU)

1.The same/ normal 


\begin{tabular}{|c|c|}
\hline & 2.Not good \\
\hline Is the neonate develop a new problem & $\begin{array}{l}\text { 1.Yes } \\
\text { 2.No }\end{array}$ \\
\hline If Yes, what is it & $\longrightarrow$ \\
\hline Breastfeeding difficulty(rooting \& sucking reflex) & $\begin{array}{l}\text { 1.Yes } \\
\text { 2.No }\end{array}$ \\
\hline Hypothermia $\mathrm{T}^{0}<36{ }^{0} \mathrm{C}$ & $\begin{array}{l}\text { 1.Yes } \\
\text { 2.No }\end{array}$ \\
\hline \multirow[t]{2}{*}{ Convulsion } & $\begin{array}{l}\text { 1.Yes } \\
\text { 2.No }\end{array}$ \\
\hline & 2.No \\
\hline Jaundice & $\begin{array}{l}\text { 1.Yes } \\
\text { 2.No }\end{array}$ \\
\hline $\begin{array}{l}\text { NICU admission after one hour of delivery? (for not admitted to NICU } \\
\text { after delivery) }\end{array}$ & $\begin{array}{l}\text { 1.Yes } \\
\text { 2.No }\end{array}$ \\
\hline If yes, the reason for $\mathrm{NICU}(\mathrm{Dx})$ & $\longrightarrow$ \\
\hline Need respiratory support & $\begin{array}{l}\text { 1.Yes } \\
\text { 2.No }\end{array}$ \\
\hline \multirow[t]{5}{*}{ If Yes, what type is it } & Mechanical ventilation \\
\hline & CPAP \\
\hline & Oxygen flow \\
\hline & Endo-tracheal tube \\
\hline & Others specify \\
\hline Is the newborn on antibiotic & 1.Yes 2.No \\
\hline \multicolumn{2}{|l|}{ Assessment at discharge } \\
\hline \multirow[t]{3}{*}{ What is the condition of the neonate at discharge } & Good /improve \\
\hline & The same \\
\hline & Dead \\
\hline If dead, what is the reason for death & 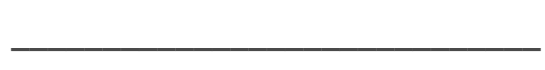 \\
\hline \multirow[t]{3}{*}{ Way of discharge } & Discharged by heath provide \\
\hline & Self-discharge/disappear \\
\hline & Death \\
\hline
\end{tabular}


Table: 3 Sociodemographic Characteristics of Women, Maternal Surveillance Study at Hospitals in Eastern Ethiopia 


\begin{tabular}{|c|c|c|c|c|}
\hline \multirow[t]{2}{*}{ Variables } & & Vaginal delivery & Cesarean & Total delivery \\
\hline & & $\mathrm{N}=1,525$ & $\mathrm{~N}=721(\%)$ & $N=2246$ \\
\hline \multirow[t]{3}{*}{ Age in years } & $15-24$ & $659(43.21)$ & 259(35.92) & $918(40.87)$ \\
\hline & $25-34$ & $741(48.59)$ & $392(54.37)$ & $1133(50.45)$ \\
\hline & $35-46$ & $125(8.20)$ & 70(9.71) & 195(8.68) \\
\hline \multirow[t]{2}{*}{ Residency } & Urban & $981(64.33)$ & $485(67.26)$ & 1466(65.27) \\
\hline & Rural & 544(35.67) & $236(32.73)$ & 780(34.73) \\
\hline \multirow[t]{6}{*}{ Ethnicity } & Oromo & $1162(76.20)$ & $482(66.85)$ & 1644(73.20) \\
\hline & Amhara & 239(15.67) & 152(21.08) & $391(17.41)$ \\
\hline & Harari & 16(1.05) & 11(1.52) & $27(1.20)$ \\
\hline & Gurage & $54(3.54)$ & $39(5.40)$ & $93(4.14)$ \\
\hline & Somali & $44(2.89)$ & $29(4.02)$ & $73(3.25)$ \\
\hline & Others & $10(0.66)$ & $8(1.10)$ & $18(0.80)$ \\
\hline \multirow[t]{7}{*}{ Occupation } & Government & $89(5.84)$ & $70(9.70)$ & 159(7.08) \\
\hline & Private & $39(2.56)$ & $38(5.27)$ & 77(3.43) \\
\hline & NGO & $10(0.66)$ & $5(0.69)$ & 15(0.67) \\
\hline & Day laborer & 19(1.25) & $4(0.55)$ & 23(1.03) \\
\hline & Self-employ & $236(15.46)$ & $113(15.67)$ & $349(15.54)$ \\
\hline & Housewife & 1123(73.64) & $486(67.40)$ & 1609(71.64) \\
\hline & Student & $9(0.59)$ & $5(0.69)$ & $14(0.62)$ \\
\hline \multirow[t]{3}{*}{ Religion } & Muslim & 1204(78.95) & $487(67.54)$ & 1691(75.29) \\
\hline & Orthodox & 287(18.82) & 215(29.81) & $502(22.35)$ \\
\hline & Protestant & $34(2.23)$ & 19(2.63) & $53(2.36)$ \\
\hline \multirow[t]{5}{*}{$\begin{array}{l}\text { Educational } \\
\text { level }\end{array}$} & $\begin{array}{l}\text { Unable read } \\
\text { \&write }\end{array}$ & 489(32.07) & $208(28.84)$ & 697(31.03) \\
\hline & 1-4grade & 241(15.80) & 87(12.06) & $328(14.60)$ \\
\hline & 5-8grade & $354(23.21)$ & 142(19.69) & 496(22.08) \\
\hline & $9-12$ grade & $309(20.26)$ & $169(23.43)$ & $478(21.28)$ \\
\hline & Diploma & $79(5.18)$ & $72(9.98)$ & 151(6.72) \\
\hline
\end{tabular}




\begin{tabular}{|lllll|}
\hline Wealth index & Degree and above & $53(3.48)$ & $43(5.96)$ & $96(4.27)$ \\
\hline & Lowest & $314(20.59)$ & $135(18.72)$ & $449(19.99)$ \\
\hline Second & $324(21.25)$ & $126(17.47)$ & $450(20.04)$ \\
\hline Middle & $320(20.98)$ & $129(17.89)$ & $449(19.99)$ \\
\hline Fourth & $311(20.39)$ & $139(19.27)$ & $450(20.04)$ \\
\hline
\end{tabular}

\section{Figures}

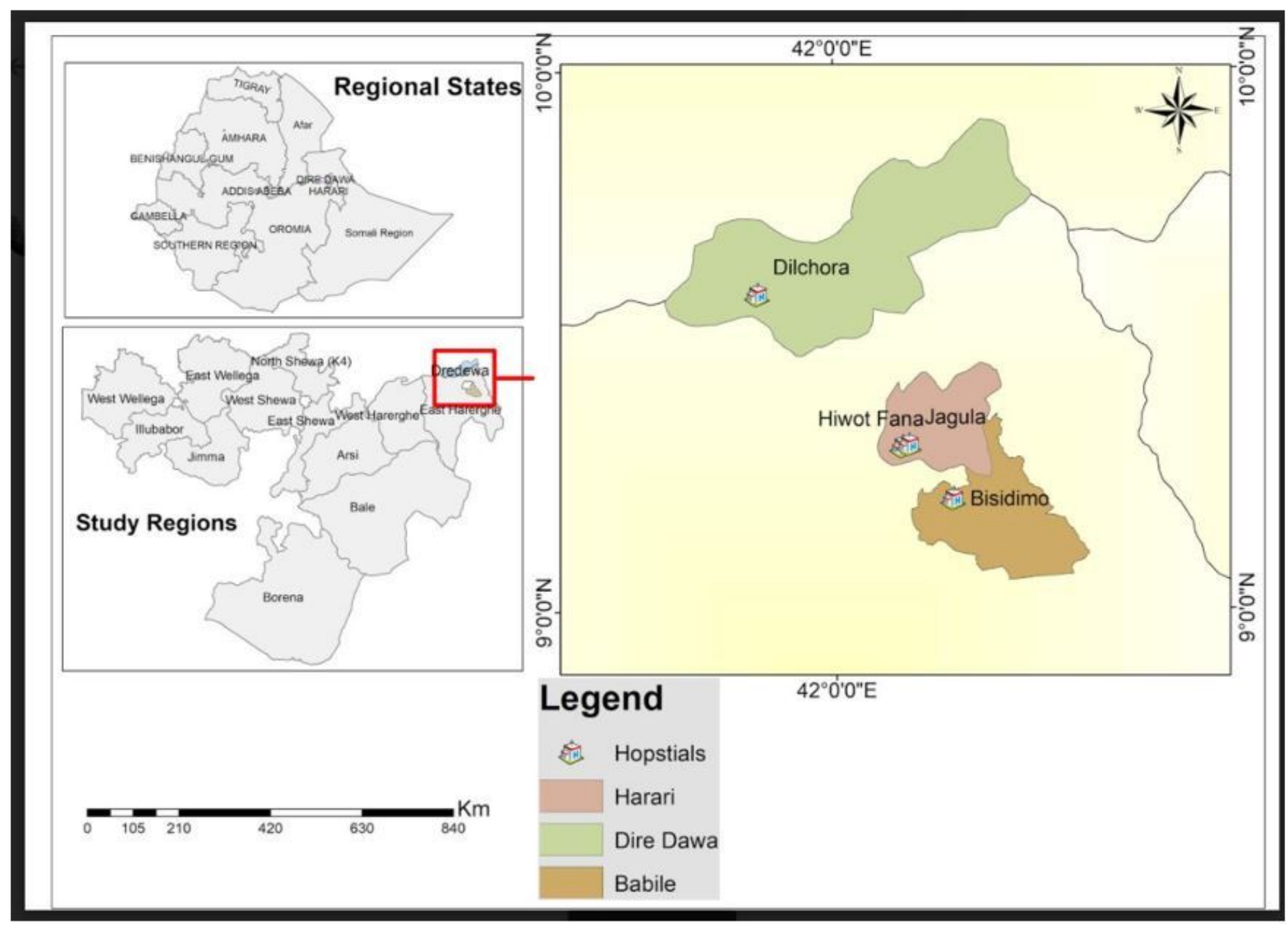

Figure 1

Map of the study area Note: The designations employed and the presentation of the material on this map do not imply the expression of any opinion whatsoever on the part of Research Square concerning the legal status of any country, territory, city or area or of its authorities, or concerning the delimitation of its frontiers or boundaries. This map has been provided by the authors. 


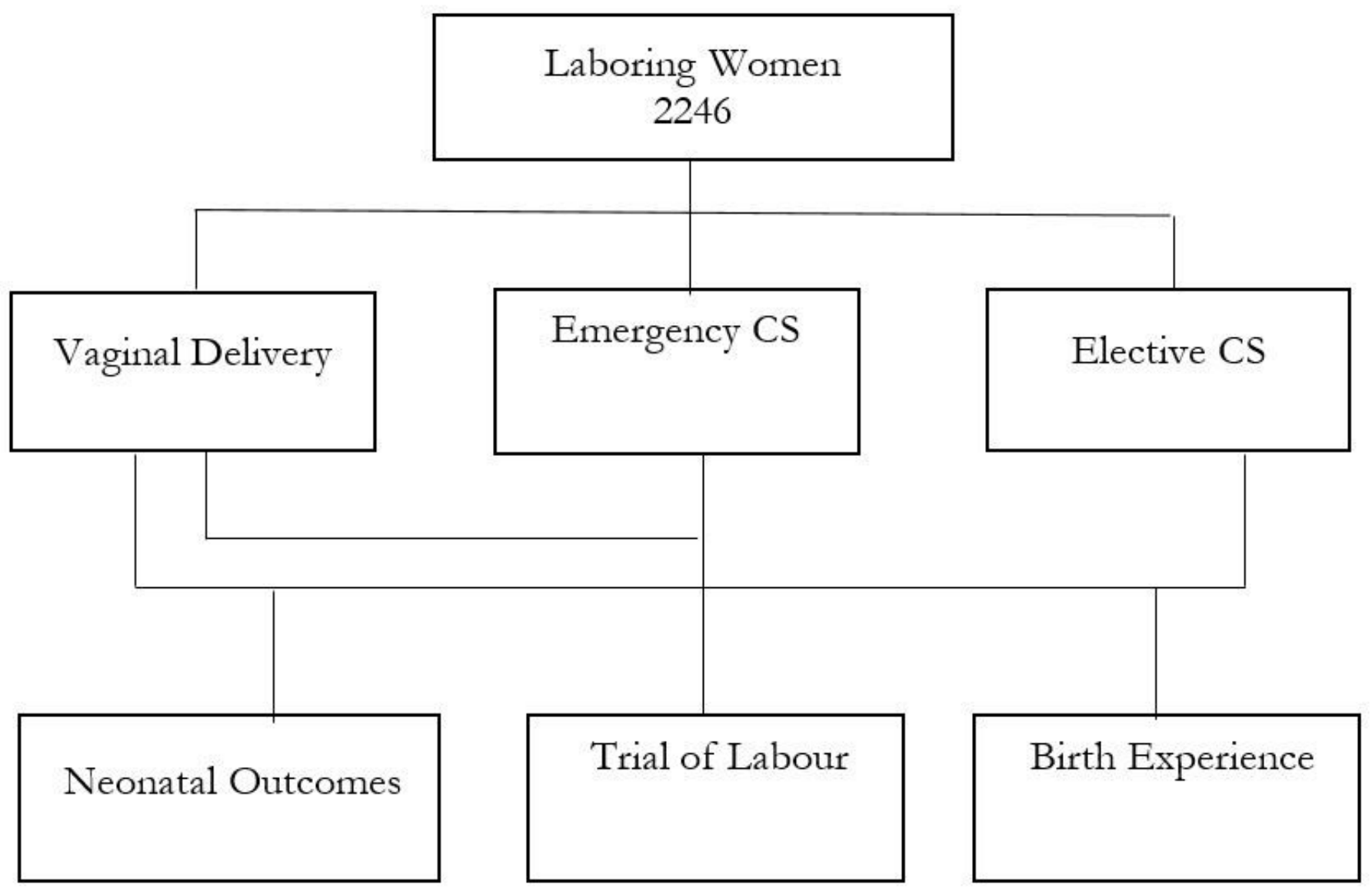

Figure 2

Study flow and population for maternal surveillance study, eastern Ethiopia 


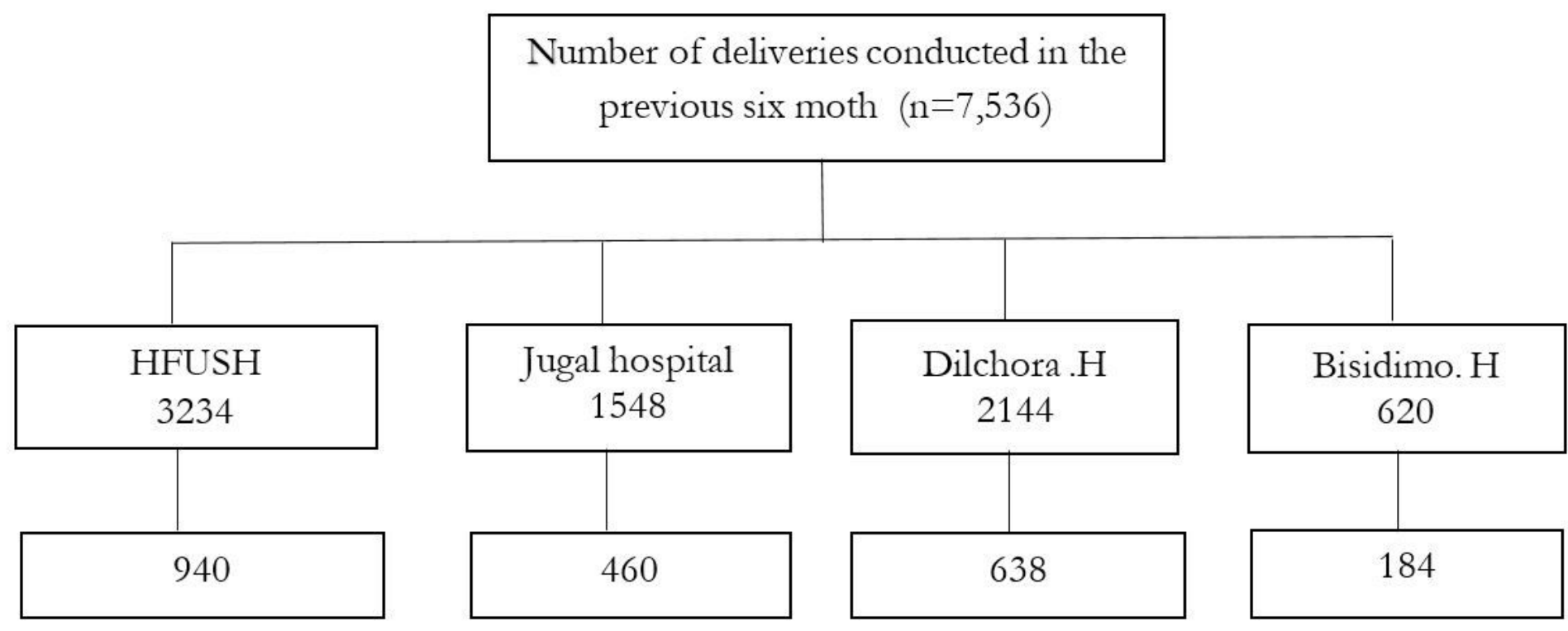

\section{Figure 3}

The previous six-month report of women who visited the hospitals for delivery and samples size selected proportionally from the respective hospitals 